Portland State University

PDXScholar

Environmental Science and Management

Faculty Publications and Presentations

$4-2000$

\title{
Multiple Source Pools and Dispersal Barriers for Galápagos Plant Species Distribution
}

\author{
J. Alan Yeakley \\ Portland State University, yeakley@pdx.edu \\ John F. Weishampel \\ University of Central Florida
}

Follow this and additional works at: https://pdxscholar.library.pdx.edu/esm_fac

Part of the Environmental Sciences Commons, and the Plant Sciences Commons

Let us know how access to this document benefits you.

\section{Citation Details}

J. Alan Yeakley and John F. Weishampel 2000. Multiple Source Pools and Dispersal Barriers for Galápagos Plant Species Distribution. Ecology 81:893-898.

This Article is brought to you for free and open access. It has been accepted for inclusion in Environmental Science and Management Faculty Publications and Presentations by an authorized administrator of PDXScholar. Please contact us if we can make this document more accessible: pdxscholar@pdx.edu. 


\title{
MULTIPLE SOURCE POOLS AND DISPERSAL BARRIERS FOR GALÁPAGOS PLANT SPECIES DISTRIBUTION
}

\author{
J. Alan Yeakley ${ }^{1,3}$ And John F. Weishampel ${ }^{2}$ \\ ${ }^{1}$ Environmental Sciences and Resources, Portland State University, Portland, Oregon 97207-0751 USA \\ ${ }^{2}$ Department of Biology, University of Central Florida, Orlando, Florida 32816-2368 USA
}

\begin{abstract}
We reexamined geographic factors explaining the number of plant species on islands in the Galápagos Archipelago. We hypothesized that plant species richness $(S)$ was related to the number of source pools and that plant species dispersal preferentially followed direct, oceanic pathways. To test different dispersal pathways from multiple source pools, the total number of islands within a given dispersal radius $(i)$ was posed as the sum of the number of line-of-sight islands $\left(C_{i}\right)$ and of the number of islands without line-ofsight connection $\left(B_{i}\right)$. In partial regression analyses, controlling for nearest island area $\left(A_{2}\right)$ and for recipient island elevation $(E)$ and area $(\ln A), C_{i}$ and $C_{i} \times E$ were found to be positively correlated with $S$ in the Galápagos for nearly all dispersal ranges from $10 \mathrm{~km}$ to $419 \mathrm{~km}$ (maximum inter-island separation). In contrast, $B_{i} \times E$ was negatively correlated with $S$ at the longest dispersal ranges. The connectivity index, $C_{i}$, multiplied by elevation, $E$, explained more variation in $S$ in the Galápagos than prior regression models using additive forms of $E, \ln A, A_{2}$, and isolation from the central island. Using the variables $C_{i} \times E$ and $\ln A$, multiple-regression models explained $>90 \%$ of the variance in both endemic and total plant species richness in the Galápagos Archipelago.

Key words: connectivity and species number; dispersal barriers, plant; elevation barriers to dispersal; extinction; Galápagos Archipelago; habitat diversity; immigration; island biogeography; oceanic pathways of plant dispersal; plant species richness; source pools and plant species richness; species dispersal in archipelagos.
\end{abstract}

\section{INTRODUCTION}

The number of species $(S)$ present on an island has been depicted as a state variable having inputs of new species by immigration and outputs of occupant species by extinction. The rates of immigration and extinction are typically depicted as functions of $S$, the island area $(A)$ and the distance $(D)$ of the island from sources of new species (Pielou 1979). Immigration rates decrease with $D$ and $S$ and increase with $A$. Extinction rates decrease with $A$ and increase with $S$ and $D . S$ has been hypothesized to approach an equilibrium value at which the immigration rate equals the extinction rate (Preston 1962, MacArthur and Wilson 1967, Brown and Lomolino 1989).

Estimation of $S$ from geographic factors in archipelagos has been a focus of ecological studies for decades (Hamilton et al. 1963, Lomolino 1986). Generally, $A$ has been found as the most significant determinant of $S$. Indices of isolation and/or additional measures of habitat diversity (such as elevation), however, have also been found significant (Johnson and Raven 1973, Wilcox 1978, Dueser and Brown 1980, Heaney 1984). Geographic isolation has been shown to affect both species richness and composition (Power 1975, Kadmon and Pulliam 1993).

The Galápagos Archipelago has been a test site for

Manuscript received 19 September 1998; accepted 15 April 1999; final version received 26 May 1999.

${ }^{3}$ E-mail: yeakley@pdx.edu ideas related to island biogeography theory. Because it is a relatively clumped and isolated archipelago, differential effects of $D$ from the South American mainland on individual islands are generally considered negligible. Plant species number has been repeatedly analyzed using multiple regression on geographic measures such as island area $(A)$, elevation $(E)$, area of the nearest island $\left(A_{2}\right)$, and isolation distance $(D)$ (Hamilton et al. 1963, Johnson and Raven 1963, Simpson 1974, Connor and Simberloff 1978, van der Werff 1983), with $E$ and $\ln A$ most correlated with total and endemic species number.

\section{Multiple source pools}

We hypothesize if a recipient island is within species dispersal range of more than one source island, additional source(s) of new individuals should increase the immigration rate and decrease the extinction rate. Any source within dispersal range should potentially contribute propagules directly to the recipient island. As a result, each additional source island within dispersal range increases the probability of new and direct arrivals on the recipient island. That is, the immigration rate should increase with the number of source islands. An increasing number of immigration sources should also reduce the extinction rate via the rescue effect (Brown and Kodric-Brown 1977). Studies have shown, for example, that patch connectivity may reduce the extinction rate (Fahrig and Merriam 1985). At equilib-

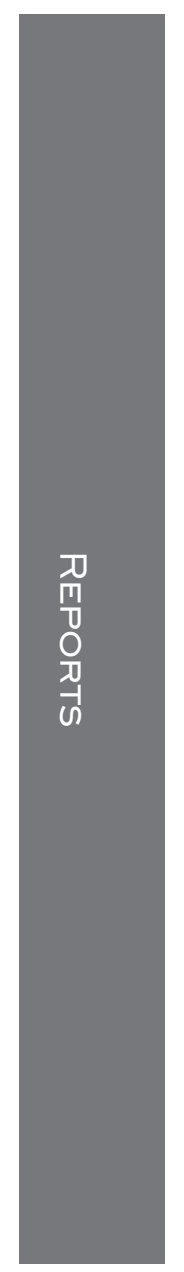


TABLE 1. Geographic variables used to predict number of total species $\left(S_{\mathrm{t}}\right)$ and endemic species $\left(S_{\mathrm{e}}\right)$.

\begin{tabular}{|c|c|c|c|c|c|c|c|c|c|c|c|}
\hline Island & $S_{\mathrm{t}}^{\dagger, \neq}$ & $S_{\mathrm{e}}^{8}$ & $A^{\S}\left(\mathrm{km}^{2}\right)$ & $E^{\dagger}(\mathrm{m})$ & $A_{2}{ }^{\S}\left(\mathrm{km}^{2}\right)$ & $C_{50}$ & $B_{50}$ & $C_{125}$ & $B_{125}$ & $C_{419}$ & $B_{419}$ \\
\hline Baltra & 58 & 23 & 25.09 & 150 & 1.84 & 8 & 3 & 14 & 12 & 16 & 12 \\
\hline Bartolomé & 31 & 21 & 1.24 & 109 & 572.33 & 6 & 3 & 9 & 15 & 11 & 17 \\
\hline Caldwell & 3 & 3 & 0.21 & 114 & 0.78 & 3 & 2 & 10 & 12 & 11 & 17 \\
\hline Champion & 25 & 9 & 0.10 & 46 & 0.18 & 4 & 1 & 14 & 8 & 16 & 12 \\
\hline Coamaño & 2 & 1 & 0.05 & 10 & 903.82 & 2 & 6 & 12 & 13 & 12 & 16 \\
\hline Daphne Major & 28 & 11 & 0.34 & 10 & 1.84 & 7 & 3 & 11 & 14 & 13 & 15 \\
\hline Darwin & 10 & 7 & 2.33 & 168 & 2.85 & 1 & 0 & 1 & 0 & 17 & 11 \\
\hline Eden & 8 & 4 & 0.03 & 10 & 17.95 & 6 & 5 & 9 & 16 & 9 & 19 \\
\hline Enderby & 2 & 2 & 0.18 & 112 & 0.10 & 5 & 0 & 17 & 5 & 18 & 10 \\
\hline Española & 100 & 26 & 58.27 & 198 & 0.57 & 2 & 0 & 13 & 3 & 19 & 9 \\
\hline Fernandina & 160 & 35 & 634.49 & 1494 & 4669.32 & 1 & 0 & 1 & 12 & 3 & 25 \\
\hline Gardner 1 & 40 & 17 & 0.57 & 49 & 58.27 & 2 & 0 & 12 & 1 & 21 & 7 \\
\hline Gardner 2 & 5 & 4 & 0.78 & 227 & 0.21 & 4 & 1 & 15 & 7 & 18 & 10 \\
\hline Genovesa & 41 & 19 & 17.35 & 76 & 129.49 & 1 & 0 & 12 & 2 & 21 & 7 \\
\hline Isabela & 435 & 89 & 4669.32 & 1707 & 634.49 & 7 & 1 & 19 & 3 & 25 & 3 \\
\hline Marchena & 47 & 23 & 129.49 & 343 & 59.56 & 2 & 0 & 11 & 4 & 17 & 11 \\
\hline Onslow & 2 & 2 & 0.01 & 25 & 0.10 & 4 & 2 & 14 & 8 & 16 & 12 \\
\hline Pinta & 165 & 37 & 59.56 & 777 & 129.49 & 1 & 0 & 9 & 4 & 16 & 12 \\
\hline Pinzon & 117 & 33 & 17.95 & 458 & 0.03 & 9 & 2 & 16 & 8 & 18 & 10 \\
\hline Las Plazas & 21 & 9 & 0.23 & 10 & 25.09 & 4 & 3 & 14 & 10 & 15 & 13 \\
\hline $\begin{array}{l}\text { Rabida } \\
\text { Ras }\end{array}$ & 75 & 30 & 4.89 & 367 & 572.33 & 8 & 1 & 14 & 9 & 15 & 13 \\
\hline San Cristóbal & 329 & 65 & 551.62 & 716 & 0.57 & 3 & 0 & 14 & 4 & 22 & 6 \\
\hline San Salvador & 282 & 81 & 572.33 & 906 & 4.89 & 9 & 0 & 17 & 6 & 20 & 8 \\
\hline Santa Cruz & 481 & 95 & 903.82 & 864 & 0.52 & 14 & 0 & 25 & 1 & 27 & 1 \\
\hline Santa Fé & 70 & 28 & 24.08 & 259 & 0.52 & 4 & 2 & 16 & 8 & 17 & 11 \\
\hline Santa Maria & 288 & 73 & 170.92 & 640 & 0.10 & 7 & 0 & 17 & 5 & 20 & 8 \\
\hline Seymour & 46 & 16 & 1.84 & 100 & 25.09 & 8 & 2 & 14 & 11 & 17 & 11 \\
\hline Tortuga & 16 & 8 & 1.24 & 186 & 17.95 & 3 & 0 & 11 & 9 & 15 & 13 \\
\hline Wolf & 22 & 12 & 2.85 & 253 & 2.33 & 1 & 0 & 1 & 0 & 19 & 8 \\
\hline
\end{tabular}

Notes: Geographic variables are defined as follows: $A=$ area of island, $A_{2}=$ area of nearest island, $B_{i}=$ number of islands without line-of-sight connection within a radius of $i \mathrm{~km}, C_{i}=$ number of islands directly connected within a radius of $i \mathrm{~km}$, and $E=$ elevation.

$\dagger$ Connor and Simberloff (1978).

‡ van der Werff (1983)

$\S$ Johnson and Raven (1973).

rium, the presence of multiple source pools should yield a higher $S$.

Isolation of individual Galápagos islands has been represented by variables including distance to nearest island, distance to the central island of the archipelago, and distance to Equador or larger islands such as Santa Cruz or Isabela (Johnson and Raven 1973, Simpson 1974). Although previous regression models have included up to three additive single-distance isolation terms, no prior independent variable has accounted for the effect of multiple sources on the probability of immigration for each island. As Connor and Simberloff (1978:221) noted on existing single-distance approaches to account for the effect of isolation in predicting species number in the Galápagos Islands, "the correlation between the frequency of immigration or 'immigration rate' and isolation is vitiated by multiple variable-sized source pools ...."

\section{Elevational barriers to dispersal}

Over long distances, intervening islands with suitable habitat may provide stepping stones that facilitate plant species dispersal (MacArthur and Wilson 1967). In the Galápagos, however, we hypothesize that tightly clumped, high-elevation islands may provide barriers to dispersing plants. The Galápagos are of relatively recent volcanic origin, with larger islands characterized by elevations up to $1707 \mathrm{~m}$. Average peak elevation among islands is $358 \mathrm{~m}$ (Table 1). As a result of steep volcanic landforms and climatic effects, habitat conditions for plant establishment vary greatly with elevation (van der Werff 1983). We hypothesize that widely varying habitat conditions along elevational gradients inhibit the stepping-stone effect, as dispersal throughout, or across, a given island might be precluded due to large shifts in moisture, temperature, or edaphic conditions along elevational gradients.

The Galápagos have received most plant-species introductions by avifaunal transport (up to 60\%), including fruits, seeds, or vegetative disseminules carried internally or attached externally (Porter 1976). Other significant mechanisms of plant-species introduction occur via wind (4-31\%) and oceanic drift (9-23\%) (Carlquist 1974, Porter 1976). These proportions contrast with locations where water-borne transport is the most important dispersal mechanism, such as the Great Lakes (Morton and Hogg 1989). Dispersal by passive mechanisms, such as via wind and water, should follow direct, oceanic connections, with islands forming barriers to further plant-propagule movement (Morton and Hogg 1989).

For active transport via avifauna, islands with sig- 


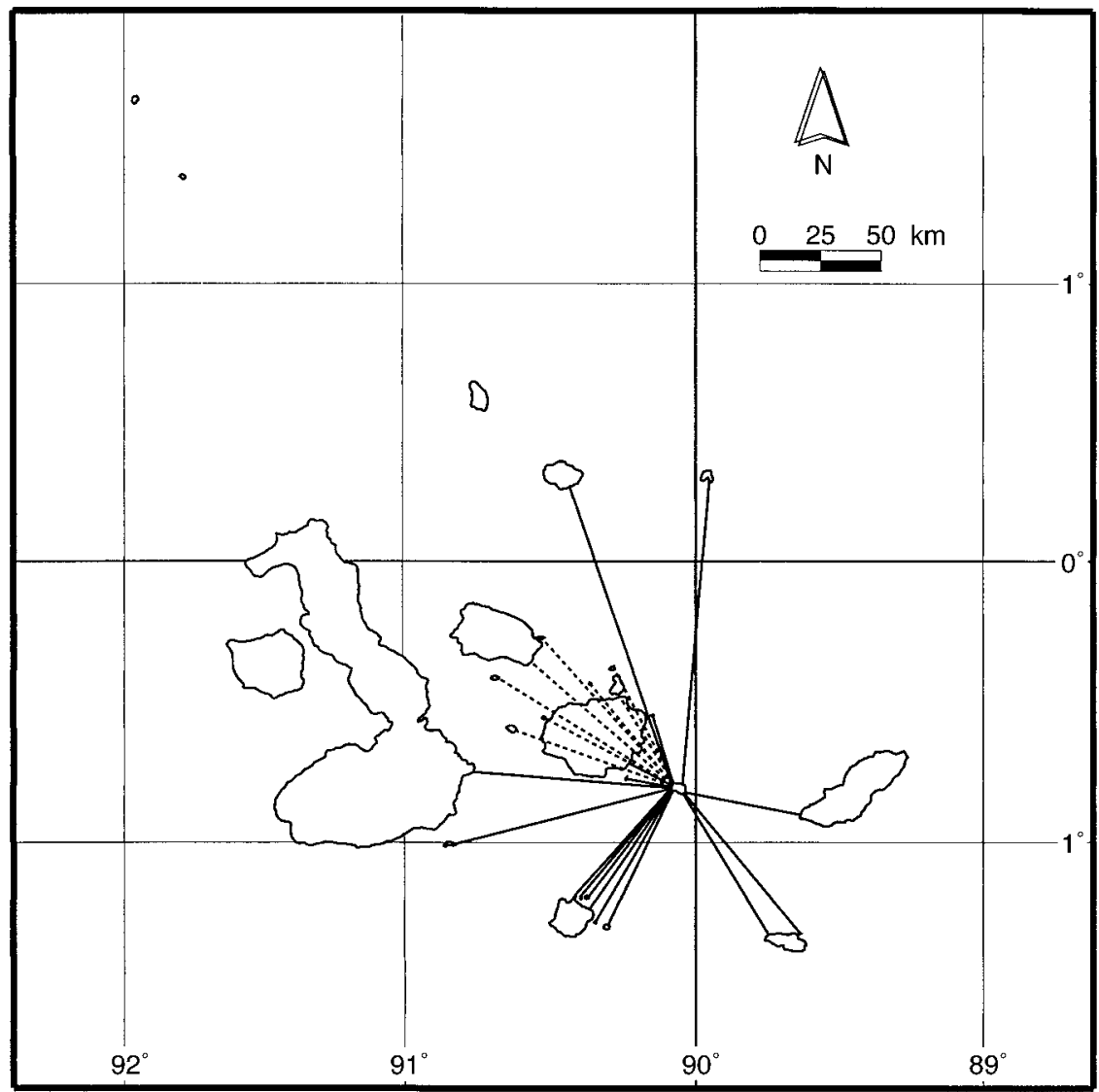

FIG. 1. The Galápagos Archipelago, including an example of the connectivity $\left(C_{i}\right)$ and barrier $\left(B_{i}\right)$ indices for a dispersal range $(i)$ of $125 \mathrm{~km}$ for the island Santa Fé. Solid lines represent line-of-sight connections with source islands; dashed lines represent barred islands, or islands without line-of-sight connection.

nificant elevations may constrain avian movement and thus dispersal of plant propagules either via egestion or physical detachment after flight. Avian species in archipelagos may differ in dispersal characteristics and with isolation (Power 1975, Diamond et al. 1976). High terrain constitutes physical boundaries for many species, constraining home ranges. While varying habitat and energy requirements among species affect flight paths, direct connections among islands should help account for flight corridors. Plant dispersal via avian transport thus would also follow direct, oceanic connections.

We propose a simple index of connectivity $\left(C_{i}\right)$ to help account for plant-species dispersal in the Galápagos. $C_{i}$ tallies the number of source islands that are directly connected, i.e., where a straight, line-of-sight, oceanic path exists between source and recipient islands (i.e., nodes, [Chen 1971]), to the recipient island at sea level within some radial dispersal distance $i$ (Fig. 1). We use $C_{i}$ to represent the degree of connectivity of each island to source islands within a given dispersal range $(i)$. The index $C_{i}$ assumes equal influence of directly connected source pools; that is, $C_{i}$ is independent of differential contributions from source pools related to source-island size, elevation, or distance from the source island within the radial distance. To test this index, we pose the total number of islands $\left(N_{i}\right)$ within a given dispersal radius $(i)$ as the sum of the number of line-of-sight islands $\left(C_{i}\right)$ and of the number of islands without line-of-sight connection $\left(B_{i}\right)$. We report results of regression analyses using $C_{i}$ as a measure of the effect of multiple source pools for both total $\left(S_{\mathrm{t}}\right)$ and endemic $\left(S_{\mathrm{e}}\right)$ plant species number in the Galápagos Archipelago.

\section{Methods}

We used geographic variables from prior studies as well as indices of multiple sources described above. These variables included area $(A)$ and elevation $(E)$ of a recipient island, distance to nearest island $\left(D_{1}\right)$, distance to the central island, Santa Cruz $\left(D_{2}\right)$, and area of adjacent island $\left(A_{2}\right)$ (Johnson and Raven 1973, Connor and Simberloff 1978). Total number of islands $\left(N_{i}\right)$, connectivity indices $\left(C_{i}\right)$ and barrier indices $\left(B_{i}\right)$ were determined for dispersal ranges of $i=10,20,30,40$, $50,75,100,125,150,175,200,300$, and 419 (maximum inter-island separation) $\mathrm{km}$ (Table 1). Distance and connectivity among islands were measured from 
TABle 2. Pearson correlation-coefficient matrix for the dependent variables $S_{\mathrm{t}}$ (total species richness) and $S_{\mathrm{e}}$ (endemic species richness) plus independent geographic variables from prior studies and new independent variables that account for multiple source pools. Significant correlations $(P<0.05)$ are shown in bold.

\begin{tabular}{|c|c|c|c|c|c|c|c|c|c|c|c|c|}
\hline & $S_{\mathrm{e}}$ & $E$ & $\ln (A)$ & $D_{1}$ & $D_{2}$ & $A_{2}$ & $C_{50}$ & $C_{125}$ & $C_{419}$ & $C_{50} \times E$ & $C_{125} \times E$ & $C_{419} \times E$ \\
\hline$S_{\mathrm{t}}$ & 0.98 & 0.81 & 0.81 & 0.00 & -0.17 & 0.10 & 0.50 & 0.51 & 0.57 & 0.89 & 0.91 & 0.90 \\
\hline$S_{\mathrm{e}}$ & & 0.79 & 0.85 & 0.00 & -0.18 & 0.07 & 0.53 & 0.51 & 0.57 & 0.89 & 0.90 & 0.88 \\
\hline$E$ & & & 0.82 & 0.01 & 0.01 & 0.53 & 0.20 & 0.13 & 0.20 & 0.74 & 0.79 & 0.83 \\
\hline $\ln (A)$ & & & & 0.25 & 0.06 & 0.25 & 0.23 & 0.22 & 0.43 & 0.67 & 0.72 & 0.75 \\
\hline$D_{1}$ & & & & & 0.61 & -0.12 & -0.50 & -0.38 & 0.23 & -0.22 & -0.10 & 0.01 \\
\hline$D_{2}$ & & & & & & 0.05 & -0.62 & -0.70 & 0.06 & -0.26 & -0.22 & -0.09 \\
\hline$A_{2}$ & & & & & & & -0.21 & -0.41 & -0.57 & 0.02 & -0.03 & 0.02 \\
\hline$C_{50}$ & & & & & & & & 0.70 & 0.32 & 0.68 & 0.53 & 0.40 \\
\hline$C_{125}$ & & & & & & & & & 0.61 & 0.61 & 0.59 & 0.46 \\
\hline$C_{419}$ & & & & & & & & & & 0.58 & 0.62 & 0.60 \\
\hline$C_{50} \times E$ & & & & & & & & & & & 0.95 & 0.90 \\
\hline$C_{125} \times E$ & & & & & & & & & & & & 0.98 \\
\hline
\end{tabular}

Notes: Independent geographic variables from prior studies: $A=$ area of island, $A_{2}=$ area of nearest island, $D_{1}=$ distance to nearest island, $D_{2}=$ distance to the central island (Santa Cruz), and $E=$ elevation. New independent variables: $C_{i}=$ connectivity index for dispersal radius of $i \mathrm{~km}$ (i.e., number of source islands with line-of-sight connection within a radius of $i \mathrm{~km}), C_{i} \times E=$ interaction term of connectivity index and elevation for dispersal radius of $i \mathrm{~km}$.

operational navigation charts (ONC M-24 and L-25 [Defense Mapping Agency, Saint Louis, Missouri, USA], January 1990), at scale 1:1000 000. Measurement error at this scale was $\sim 1 \mathrm{~km} . N_{i}, C_{i}$ and $B_{i}$ were used alone and combined with measures of recipientisland habitat diversity, e.g., $C_{i} \times E$ and $C_{i} \times A$.

Although Galápagos flora are constantly being updated (e.g., Adsersen 1989), for continuity with past regression analyses we used total species richness $\left(S_{\mathrm{t}}\right)$ from Connor and Simberloff (1978), as updated by van der Werff (1983). We used endemic species richness $\left(S_{\mathrm{e}}\right)$, where endemism is for the entire archipelago, from Johnson and Raven (1973). We determined correlations among geographic variables and plant species number. Partial regression analyses were used to test relative contributions of multiple source indices, partialling out previously used geographic factors $\left(E, \ln A, A_{2}\right)$ that were most correlated with plant species number. Stepwise multiple-regression analyses were performed to determine best-fitting predictor equations, with $P=$ 0.05 as selection and deselection criteria. In multipleregression analyses, predictor variables included variables from prior studies $\left(A, \ln A, E, \ln E, A_{2}, D_{1}, D_{2}\right)$ plus $C_{\mathrm{i}}, B_{\mathrm{i}}, N_{\mathrm{i}}$, for all dispersal ranges measured, as well as interaction terms (e.g., $C_{i} \times E, C_{i} \times A$ ).

\section{REsults}

Simple Pearson correlations showed positive relationships between either total species richness $\left(S_{\mathrm{t}}\right)$ or endemic species richness $\left(S_{\mathrm{e}}\right)$ and the interaction term of connectivity ( $C_{i}$, where $i$ is the radial dispersal distance) and elevation, $C_{i} \times E$ (Table 2). Additionally, while single-source measures of distance (to nearest island, $D_{1}$, to central island [Santa Cruz] $D_{2}$ ) were uncorrelated with species richness $(S)$, the connectivity index $\left(C_{i}\right)$ was correlated with $S$ beyond a $10-\mathrm{km}$ dispersal range. In partial correlations with $S_{\mathrm{t}}$, controlling for elevation $(E)$, area $(\ln A)$, and area of the nearest island $\left(A_{2}\right), C_{i}$ remained correlated with $S_{\mathrm{t}}$ for nearly all dispersal ranges (Fig. 2a). The total number of source islands $\left(N_{i}\right)$ was correlated with $S_{\mathrm{t}}$ over a shorter dispersal range and with a consistently lower correlation strength than $C_{i}$, and the index of unconnected or barred islands $\left(B_{\mathrm{i}}\right)$ was not correlated with $S_{\mathrm{t}}$ for any dispersal range (Fig. 2a). Partial correlation between $S_{\mathrm{t}}$ and $C_{i} \times A$, controlling for $E, \ln A$, and $A_{2}$, showed no relationship, while partial correlation between $S_{\mathrm{t}}$ and $C_{i} \times E$ showed a positive relationship for all dispersal ranges except $i=200 \mathrm{~km}$ (Fig. 2b). In contrast, partial correlations between $S_{\mathrm{t}}$ and $B_{i} \times E$ showed a negative correlation at dispersal ranges $\geq 300 \mathrm{~km}$.

Despite the update from van der Werff (1983), multiple-regression models based only on prior geographic predictor variables remained consistent with prior regression results, in terms of both predictor variables and coefficients of determination (Table 3). Prior additive models explained $64-79 \%$ of the variance in endemic and total species number. In contrast, the interaction term between connectivity and recipient-island elevation $\left(C_{i} \times E\right)$ alone explained at least $79 \%$ of the variance in either endemic or total plant species number. Regression models that included recipient-island area $(\ln A)$ and $C_{i} \times E$ at multiple dispersal ranges explained $>90 \%$ of the variance (Table 3 ).

\section{DISCUSSION}

While prior single-distance measures were uncorrelated with plant species richness, $S$, an index of multiple sources within dispersal range, $C_{i}$, was found positively correlated with $S_{t}$ (total species richness) in the Galápagos Archipelago for dispersal ranges from 10 $\mathrm{km}$ to $300 \mathrm{~km}$ (Fig. 2a). Moreover, a measure of multiple sources $\left(C_{i}\right)$ multiplied by elevation $(E)$, a correlate of habitat diversity, explained more variation in $S$ in the Galápagos than prior regression models (Table 3 ) that used additive forms of $E, \ln A,(A=$ area of island), $A_{2}$ (area of nearest island), and isolation from the central island $\left(D_{2}\right)$. While area $(\ln A)$ yet claimed a 


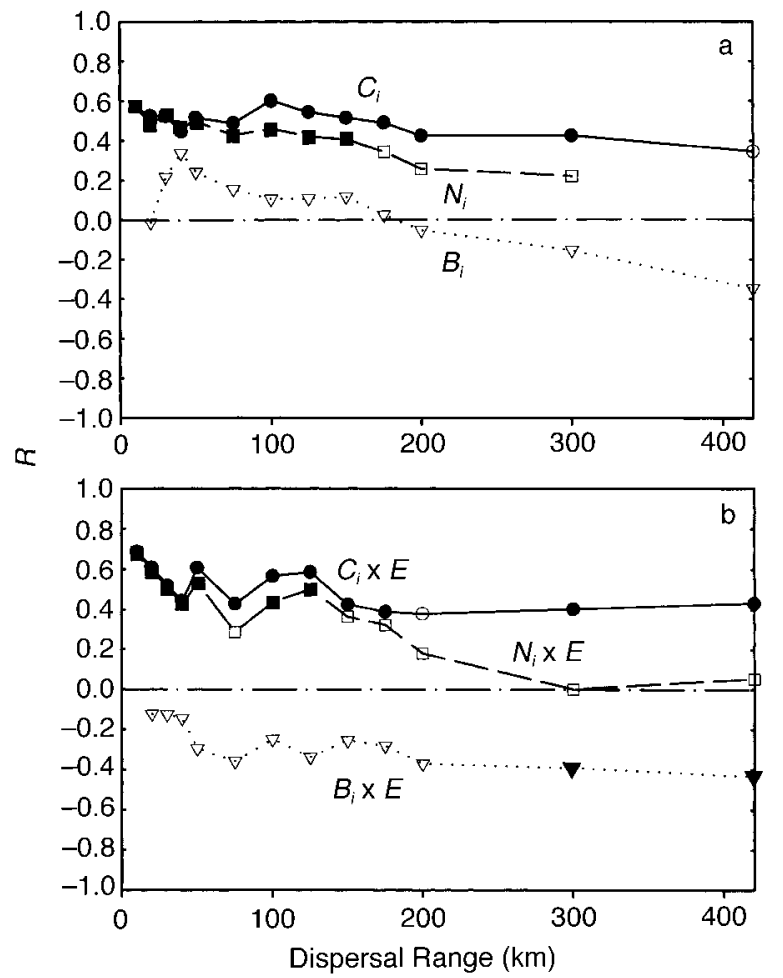

FIG. 2. Partial correlations, $R$, between multiple source indices and total plant species number $\left(S_{\mathrm{t}}\right)$ in the Galápagos Archipelago, where variation due to elevation $(E)$, area of island $(\ln A)$, and area of nearest island $\left(A_{2}\right)$ are all controlled. Solid symbols show significant correlations $(P<0.05)$ for: (a) Partial correlations between $S_{\mathrm{t}}$ and multiple-source indices of total number of islands $\left(N_{i}\right)$, island connectivity $\left(C_{i}\right)$, and island barriers $\left(B_{i}\right)$, within dispersal range $i$; (b) Partial correlations between $S_{\mathrm{t}}$ and multiple-source indices multiplied by elevation of recipient island $\left(N_{i} \times E, C_{i} \times E\right.$, and $\left.B_{i} \times E\right)$.

significant portion of the variance in species number, $C_{i} \times E$ explained more variance than either area or elevation alone at any dispersal distance.

In addition to disregarding effects of multiple sources and dispersal barriers, no previous Galápagos flora study addressed interactive effects of the factors; i.e., in prior studies all terms in the analyses were additive. Using additive terms requires an assumption of independence among predictor variables (Martin 1981). The connectivity index, $C_{i}$, was very simple, and was found independently correlated with $S$ (Fig. 2a). Our results further show that an interdependence existed between a variable of dispersal sources $\left(C_{i}\right)$ and a variable of habitat diversity $(E)$ in determining $S$ (Fig. 2b). van der Werff (1983) showed that elevation differences on islands in the Galápagos corresponded to xeric plant habitat in lowlands and mesic plant habitat in middle-to-higher elevations primarily due to climatic interactions with landform. The results here indicate that habitat diversity on elevational gradients, combined with direct, interisland pathways of dispersal,
TABLE 3. Multiple stepwise regression results for numbers of total plant species $\left(S_{t}\right.$; Connor and Simberloff 1978, van der Werff 1983) and for numbers of endemic plant species $\left(S_{\mathrm{e}}\right.$; Johnson and Raven 1973) in the Galápagos Archipelago.

\begin{tabular}{clc}
\hline $\begin{array}{c}\text { Dependent } \\
\text { variable }\end{array}$ & \multicolumn{1}{c}{ Independent variables $\dagger$} & $\begin{array}{c}\text { Adjusted } \\
R^{2}\end{array}$ \\
\hline$S_{\mathrm{t}}$ & $E$ & 0.647 \\
& $E, A_{2}$ & 0.793 \\
& $C_{125} \times E$ & 0.826 \\
& $C_{125} \times E, \ln (A)$ & 0.873 \\
& $C_{125} \times E, \ln (A), C_{10} \times E$ & 0.899 \\
$S_{\mathrm{e}}$ & $C_{125} \times E, \ln (A), C_{10} \times E, C_{75} \times E$ & 0.935 \\
& $\ln (A)$ & 0.717 \\
& $\ln (A), D_{2}$ & 0.763 \\
& $C_{50} \times E$ & 0.786 \\
& $C_{50} \times E, \ln (A)$ & 0.905 \\
\hline
\end{tabular}

Notes: For both $S_{\mathrm{t}}$ and $S_{\mathrm{e}}$, prior best-fitting regression models are shown, followed by improved models from the present study. All independent variables shown below were significant in partial $F$ tests $(P<0.05)$.

$\dagger$ Defined in Tables 1 and 2.

provide the strongest explanation for plant-species dispersal patterns.

The most correlated dispersal range in this study was $125 \mathrm{~km}$, which is close to the mean interisland distance in the Galápagos Archipelago $(112 \mathrm{~km})$. We found that while connectivity variables $\left(C_{i}\right.$ or $\left.C_{i} \times E\right)$ were positively correlated with the number of both endemic and total species for all dispersal ranges, an index of island barriers combined with elevation $\left(B_{i} \times E\right)$ was negatively correlated with $S$ for the longest dispersal ranges (Fig. 2b).

These results show that multiple source pools can have a significant effect on species number in archipelagos, by either increasing immigration of new species or decreasing extinction, or by both processes simultaneously. These results also indicate that oceanic pathways in relatively tightly clumped and high-elevation archipelagos can play an important role in plant dispersal. These results further suggest that habitat changes along elevation gradients on islands in the $\mathrm{Ga}$ lápagos Archipelago generally form barriers, rather than stepping stones, to plant species dispersal.

\section{ACKNOWLEDGMENTS}

We appreciate the comments of E. F. Connor, R. B. Forbes, M. A. Huston, J. Kolasa, H. O. Whittier, J. J. Wiorkowski, and one anonymous reviewer.

\section{Literature Cited}

Adsersen, H. 1989. The rare plants of the Galápagos Islands and their conservation. Biological Conservation 47:49-77.

Brown, J. H., and A. Kodric-Brown. 1977. Turnover rates in insular biogeography: effect of immigration and extinction. Ecology 58:445-449.

Brown, J. H., and M. V. Lomolino. 1989. Independent discovery of the equilibrium theory of island biogeography. Ecology 70:1954-1957.

Carlquist, S. 1974. Island biology. Columbia University Press, New York, New York, USA. 
Chen, W. 1971. Applied graph theory. North Holland, New York, New York, USA.

Connor, E. F., and D. Simberloff. 1978. Species number and compositional similarity of the Galápagos flora and avifauna. Ecological Monographs 48:219-248.

Diamond, J. M., M. E. Gilpin, and E. Mayr. 1976. Speciesdistance relation for birds of the Solomon Archipelago, and the paradox of the great speciators. Proceedings of the National Academy of Sciences (USA) 73:2160-2164.

Dueser, R. D., and W. C. Brown. 1980. Ecological correlates of insular rodent diversity. Ecology 61:50-56.

Fahrig, L., and G. Merriam. 1985. Habitat patch connectivity and population survival. Ecology 66:1762-1768.

Hamilton, T. H., R. H. Barth, and G. L. Bush. 1963. Species abundance: natural regulation of insular variation. Science 142: $1575-1577$.

Heaney, L. R. 1984. Mammalian species richness on islands on the Sunda Shelf, Southeast Asia. Oecologia 61:11-17.

Johnson, M. P., and P. H. Raven. 1973. Species number and endemism: the Galápagos Archipelago revisited. Science 179:893-895.

Kadmon, R., and H. R. Pulliam. 1993. Island biogeography: effect of geographic isolation on species composition. Ecology 74:977-981.

Lomolino, M. V. 1986. Mammalian community structure on islands: the importance of immigration, extinction and in- teractive effects. Biological Journal of the Linnean Society 28: $1-21$.

MacArthur, R. H., and E. O. Wilson. 1967. The theory of island biogeography. Princeton University Press, Princeton, New Jersey, USA.

Martin, T. E. 1981. Species-area slopes and coefficients: a caution on their interpretation. American Naturalist 118: 823-837.

Morton, J. K., and E. H. Hogg. 1989. Biogeography of islands floras in the Great Lakes. II. Plant dispersal. Canadian Journal of Botany 67:1803-1820.

Pielou, E. C. 1979. Biogeography. John Wiley \& Sons, New York, New York, USA.

Porter, D. M. 1976. Geography and dispersal of Galápagos Islands vascular plants. Nature 264:745-746.

Power, D. M. 1975. Similarity among avifaunas of the Galápagos Islands. Ecology 56:616-626.

Preston, F. W. 1962. The canonical distribution of commonness and rarity: part I. Ecology 43:185-215.

Simpson, B. B. 1974. Glacial migrations of plants: island biogeographical evidence. Science 185:698-700.

van der Werff, H. 1983. Species number, area and habitat diversity in the Galápagos Islands. Vegetatio 54:167-175.

Wilcox, B. A. 1978. Supersaturated island faunas: a speciesage relationship for lizards on post-pleistocene land-bridge islands. Science 199:996-998. 